Pensamiento Crítico Vol. $18 \mathrm{~N}^{\circ} 1$, pp. 7-42

\title{
El rol de China en la economía asiática e implicancias para la economía mundial
}

\author{
Carlos Aquino Rodríguez
}

\section{RESUMEN}

China es un actor clave en la economía asiática. Es el mayor mercado para la mayoría de ellos, es la fábrica de Asia, y del mundo, donde partes y componentes producidos por el resto son ensamblados en China y de ahí exportados al mundo. Concentra la mayor inversión de varios países asiáticos. China asimismo está cambiando el motor de crecimiento de su economía de las exportaciones e inversión al consumo interno. La apreciación de su moneda el yuan ayuda en este sentido.

Se espera que China se convierta en uno de los motores, el mayor, de la economía mundial. De hecho ya lo es para varios países, entre ellos el Perú.

\section{ABSTRACT}

China is a key actor in the Asian economy. It is the biggest market for them, the factory of Asia and the world, where parts and components produced by them are assembled in China and exported to the world. It concentrate most of investment of several Asian countries, China also is changing the engine of its economy from 


\section{Pensamiento Crítico Vol. I8. Nº}

exports and investment to consumption. The appreciation of its currency, the Yuan, helps in this direction.

It is expected that China will become one of the engines, the main one, of the world economy. In fact, it is already for many countries, like to Peru.

Palabras Claves: China como motor de la economía mundial, apreciación del yuan, relaciones Perú China

El presente estudio analiza el rol de China en la economía asiática y mundial. Ese país se está convirtiendo en la fábrica del mundo pero también se podrá convertir en el mayor mercado de consumo del mundo. El rol de este país es clave para entender el crecimiento de la región asiática y del mundo en general.

El estudio es más bien descriptivo pues se trata de informar sobre un tema que ha sido poco estudiado. El autor ha escrito diversos artículos e incluso libros sobre este tema con el objetivo de difundir la realidad de China, de Asia, y la importancia de que el Perú conozca de ellos para poder tener una mejor relación y sacar más provecho de esta.

\section{Problema:}

1. China adquiere un papel más importante en la economía mundial, pero China está en el centro de una red de integración en Asia, donde el mayor comercio e inversión son los principales componentes.

2. El dinamismo de China puede convertirlo en el motor de la economía mundial.

3. La apreciación de su moneda puede acelerar el consumo interno y que China se convierta en el mayor mercado también del mundo.

\section{Objetivo de la investigación:}

1. Dar a conocer como el dinamismo chino es resultado de una mayor integración económica en Asia.

2. Explicar como el crecimiento chino hará que se convierta en el motor de la economía mundial y actor importante para el resto de países del mundo. 


\section{Carlos Aquino Rodríguez}

\section{Hipótesis:}

1. Hay una estrecha relación entre China y los países asiáticos, dada por el mayor comercio, inversión y acuerdos comerciales entre ellos.

2. China está cambiando el motor de crecimiento de su economía de las exportaciones e inversión al consumo interno.

3. La apreciación de su moneda, el yuan, ayuda a lo anterior, al incrementar el poder adquisitivo de su economía y consumidores.

\section{Índice:}

1. Introducción

2. Relaciones económicas entre China, Japón, Corea y Taiwán

3. ¿Cuando y como China cambiara el motor de su desarrollo económico de las exportaciones e inversión al consumo interno?

4. ¿Como la apreciación del yuan acelerara el cambio a China como el timonel del crecimiento de la economía mundial?

5. Conclusiones

\section{INTRODUCCIÓN}

Este estudio discutirá el rol de China en la economía asiática y las implicancias para la economía mundial. China es actualmente el mayor socio comercial de muchos países asiáticos, que venden bienes intermedios y de capital a China que son transformados en bienes finales, y luego exportados hacia ellos y al mundo entero. El enorme stock de mano de obra barata de China está transformando al país en la fábrica del mundo. 


\section{Pensamiento Crítico Vol. I8. Nº}

Pero China también se está convirtiendo por sí mismo en un vasto mercado para los bienes finales que ensambla. Conforme su ingreso aumenta, sus consumidores demandan todo tipo de bienes, no solo de lo que producen sino de productos del extranjero. Esto hará que el mercado chino se convierta en el principal motor del crecimiento del país y del mundo. La apreciación del yuan, al incrementar el poder adquisitivo de sus consumidores está trabajando en esa dirección.

Los mercados de los países asiáticos se están convirtiendo en muy importante para China. El comercio en ambos sentidos entre China y los países asiáticos es cada vez mayor. De hecho lo que tenemos entre China y sus vecinos de Asia es una red internacional de producción resultado del comercio en partes y componentes a lo largo de una cadena de suministro. Arreglos de producción vertical significa comercio de componentes usados en la producción de bienes finales.

Los acuerdos de libre comercio (ALC) entre los países asiáticos está acelerando el flujo de bienes, servicios e inversión en la región, como por ejemplo el ALC que existe entre China y los miembros del ASEAN.

China es ahora uno de los principales motores de la economía mundial. También para los países latinoamericanos como el Perú, el gigante asiático ha permitido a estos países, al comprarles materias primas, experimenten altas tasas de crecimiento. También, al proveerles de productos manufacturados baratos, ha ayudado a mejorar el nivel de vida de sus poblaciones.

Esta es la razón por la que es importante estudiar la economía china, como evoluciona, sus relaciones con los países asiáticos y su impacto en la economía mundial.

Este estudio tiene cuatro partes: La primera vera las relaciones entre China, Japón, Corea y Taiwán, dado el hecho de que, como es bien conocido, estas tres economías son las principales proveedores de capital, maquinaria, y partes y componentes para sus firmas establecidas en China o para las compañías chinas que las usan en el ensamblaje final destinado a las exportaciones o para el mercado interno. ¿Cuán importante es esta relación, y como los acuerdos comerciales, por ejemplo el alcanzado entre China 


\section{Carlos Aquino Rodríguez}

y Taiwán están incrementando esta relación? ¿En qué industrias esta relación es importante para China y para los países involucrados?

Segundo, se verá cuando y como China cambiara su motor de crecimiento de las exportaciones e inversión al consumo. La población china de 1.34 mil millones de habitantes con un ingreso per cápita de 4,400 dólares está haciendo el mercado interno chino muy dinámico y atractivo. Las compañías chinas cada vez producen más para el mercado interno que para el mercado extranjero. ¿Cuando China se transformara de la fábrica del mundo al mercado del mundo?

Tercero, ¿̇como la apreciación del yuan acelerara el cambio a China como el motor de la economía mundial? Por años, hasta Julio del 2005, el yuan estaba fijo a un valor de 8.2 por dólar, pero desde ese momento se aprecia hasta alcanzar un valor de 6.8 por dólar hasta julio del 2008. Se quedo fijo en ese valor hasta julio del 2010 cuando otra vez empezó a apreciarse y ahora, a agosto del 2012, ha alcanzado un valor de 6.35 por dólar. Continuara apreciándose aunque a una velocidad menor. Esto incrementara el poder adquisitivo de los chinos para comprar bienes extranjeros. Especialmente en una situación en que el crecimiento de las economías desarrolladas de Europa, Japón y EE.UU. es bajo, el mundo necesita un motor de crecimiento. Se espera que China se convierta en ese motor.

Por último, se darán algunas conclusiones.

\section{Relaciones Económicas entre China, Japón, Corea y Taiwán}

El crecimiento económico chino, junto con el de otros países en desarrollo, emergentes, está liderando el crecimiento de la economía mundial. De acuerdo a estadísticas del Fondo Monetario Internacional en sus proyecciones al 12 de julio del 2012, el año 2012 la economía mundial crecerá 3.5\%, pero las economías avanzadas solo crecerán $1.4 \%$, y las economías emergentes y en desarrollo crecerán $5.6 \%$. Las economías desarrolladas crecerán poco y las de la zona euro decrecerán un $-0.3 \%$. Así que son las economías emergentes las que están levantando el crecimiento económico mundial. Entre ellas, China crecerá un $8 \%$. Ver Cuadro 1. 


\section{Pensamiento Crítico Vol. 18. N I}

Cuadro 1: World economic growth by regions and countries (Year over year, percent change)

\begin{tabular}{|c|c|c|c|c|}
\hline & 2010 & 2011 & 2012 Projection & 2013 Projection \\
\hline World Output & 5.3 & 5.9 & 3.5 & 3.9 \\
\hline Advanced Economies & 3.2 & 1.6 & 1.4 & 1.9 \\
\hline United States & 3.0 & 1.7 & 2.0 & 2.3 \\
\hline Euro Area & 1.9 & 1.5 & -0.3 & 0.7 \\
\hline Japan & 4.4 & -0.7 & 2.4 & 1.5 \\
\hline $\begin{array}{l}\text { Newly Industrializing Asian } \\
\text { Economies }\end{array}$ & 8.5 & 4.0 & 2.7 & 4.2 \\
\hline $\begin{array}{l}\text { Emerging and } \\
\text { Developing economies }\end{array}$ & 7.5 & 6.2 & 5.6 & 5.9 \\
\hline $\begin{array}{l}\text { Commonwealth of } \\
\text { Independent States }\end{array}$ & 4.8 & 4.9 & 4.1 & 4.1 \\
\hline - Russia & 4.3 & 4.3 & 4.0 & 3.9 \\
\hline $\begin{array}{l}\text { Developing Asia } \\
\text { - China } \\
\text { - India } \\
\text { - ASEAN } 5\end{array}$ & $\begin{array}{c}9.7 \\
10.4 \\
10.8 \\
7.0\end{array}$ & $\begin{array}{l}7.8 \\
9.2 \\
7.1 \\
4.6\end{array}$ & $\begin{array}{l}7.1 \\
8.0 \\
6.1 \\
5.4\end{array}$ & $\begin{array}{l}7.5 \\
8.5 \\
6.5 \\
6.1\end{array}$ \\
\hline $\begin{array}{l}\text { Latin America and the } \\
\text { Caribbean } \\
\text { - Brazil } \\
\text { - Mexico }\end{array}$ & $\begin{array}{l}6.2 \\
7.5 \\
5.6\end{array}$ & $\begin{array}{l}4.5 \\
\\
2.7 \\
3.9\end{array}$ & $\begin{array}{l}3.4 \\
\\
2.5 \\
3.9\end{array}$ & $\begin{array}{l}4.2 \\
4.6 \\
3.6\end{array}$ \\
\hline
\end{tabular}

Source: World Economic Outlook Update, July 16, 2012, from Table 1 http://www.imf.org/external/pubs/ft/ weo/2012/update/02/index.htm

Las relaciones económicas entre las 3 más grandes economías en el Este Asiático y Taiwán es cada vez más estrecha. China es la segunda economía más grande en el mundo, Japón es la tercera y Corea (Corea del Sur) es la catorceava. Ver Cuadro 2. Como se ve, Corea está creciendo rápido, y a esa velocidad en unos años mas estará entre las diez economías más grandes del mundo. 


\section{Carlos Aquino Rodríguez}

Cuadro 2: Countries by GDP Size, USD millions

\begin{tabular}{lcc}
\hline & $\begin{array}{c}\text { Gross Domestic Product } \\
\text { (GDP), Year 2010 }\end{array}$ & $\begin{array}{c}\text { Average annual \% growth } \\
\mathbf{2 0 0 0 - 2 0 1 0}\end{array}$ \\
\hline United States & $14,582,400$ & 1.9 \\
China & $5,878,629$ & 10.8 \\
Japan & $5,497,813$ & 0.9 \\
Germany & $3,309,669$ & 1.0 \\
France & $2,560,002$ & 1.3 \\
United Kingdom & $2,246,079$ & 1.6 \\
Brazil & $2,087,890$ & 3.7 \\
Italia & $2,051,412$ & 0.3 \\
India & $1,729,010$ & 8.0 \\
Canada & $1,574,072$ & 2.0 \\
Russia & $1,479,819$ & 5.4 \\
Spain & $1,407,405$ & 2.4 \\
Mexico & $1,039,662$ & 2.2 \\
Korea & $1,014,483$ & 4.1 \\
\hline
\end{tabular}

Source: World Bank, "World Development Report 2012", Selected World Development Indicators 2012, from Table 4.

En la región del Este Asiático China es la economía más grande, Japón es la segunda, Corea es la tercera, y Taiwán es la sexta (Indonesia es la cuarta y Australia es la quinta). Ver Cuadro 3. 


\section{Pensamiento Crítico Vol. 18. Nº}

Cuadro 3: Main Economic Indicators of China, Japan, Korea and Taiwan

\begin{tabular}{|c|c|c|c|c|c|}
\hline & $\begin{array}{l}\text { GDP } \\
\text { USD } \\
\text { billion } \\
(2010)\end{array}$ & $\begin{array}{l}\text { GDP per } \\
\text { capita } \\
\text { USD } \\
(2010)\end{array}$ & $\begin{array}{l}\text { Population } \\
\text { Million } \\
(2010)\end{array}$ & $\begin{array}{c}\text { Merchandise } \\
\text { exports } \\
\text { USD billion, } \\
2011 \text { (World } \\
\text { share in } \\
\text { parenthesis) }\end{array}$ & $\begin{array}{l}\text { Merchandise } \\
\text { imports } \\
\text { USD billion, } \\
2011 \text { (World } \\
\text { share in } \\
\text { parenthesis) }\end{array}$ \\
\hline China & $5,926.6$ & 4,428 & $1,338.30$ & $1,899(10.4)$ & $1,743(9.5)$ \\
\hline Japan & $5,458.8$ & 42,830 & 127.45 & $823(4.5)$ & 854 (4.6) \\
\hline Korea & $1,014,4$ & 20,756 & 48.87 & $555(3.0)$ & $524(2.9)$ \\
\hline Taiwan (2011) & 466.4 & 20,122 & 23.19 & 308 (1.7) & 281 (1.5) \\
\hline $\begin{array}{l}\text { Memorandum: } \\
\text { Trade in } \\
\text { Commercial } \\
\text { Services: }\end{array}$ & & & & $\begin{array}{l}\text { Exports } \\
\text { USD billion, } \\
2011 \text { (World } \\
\text { share in } \\
\text { parenthesis) }\end{array}$ & $\begin{array}{l}\text { Imports } \\
\text { USD billion, } \\
2011 \text { (World } \\
\text { share in } \\
\text { parenthesis) }\end{array}$ \\
\hline China & & & & $182(4.4)$ & $236(6.1)$ \\
\hline Japan & & & & $143(3.4)$ & 135 (4.3) \\
\hline Korea & & & & 94 (2.3) & 98 (2.5) \\
\hline Taiwan & & & & $46(1.1)$ & $41(1.1)$ \\
\hline
\end{tabular}

Source: For GDP, GDP per capita, and population APEC http://statistics.apec.org/, for trade figures WTO "World Trade Report 2012", Appendix Table 3 and Table1-3 page 22

Estas cuatro economías no solo están entre las más grandes en el mundo, sino están también entre los mayores exportadores e importadores. De acuerdo a la Organización Mundial del Comercio (OMC) en el año 2011 China fue el primer exportador de bienes, Japón el cuarto, Corea el séptimo y Taiwán el diecisieteavo. Ver cuadro 4. Entre ellos suman casi un quinto del total del comercio mundial (19.6\% de las exportaciones y $19.5 \%$ de las importaciones). Ver cuadro 3. Por supuesto China es el más grande y su porcentaje en el comercio mundial seguirá incrementándose tal como su tamaño en la economía mundial se incrementa. 


\section{Carlos Aquino Rodríguez}

El comercio en servicios está creciendo también a una tasa alta, y aunque en el 2011 su valor fue de menos de un cuarto del comercio en mercancías, se convierte cada vez más importante para las economías asiáticas. En el 2011 el valor de las exportaciones de mercancías fue de 18.217 billones de dólares, mientras que las exportaciones de servicios comerciales fueron de 4.149 billones de dólares ${ }^{1}$. Como se ve en el Cuadro 3 arriba, la participación de las cuatro economías en estudio en las exportaciones de servicios comerciales es pequeña, especialmente para China, pero se incrementara pues China y las economías asiáticas continúan creciendo.

Cuadro 4: Merchandise trade: Leading exporters and importers, 2011 (in USD billion and \%)

\begin{tabular}{|c|c|c|c|c|c|c|c|c|c|}
\hline Rank & Exporters & Value & Share & $\begin{array}{l}\text { Annual Percentage } \\
\text { change }\end{array}$ & Rank & Importers & Value & Share & $\begin{array}{c}\text { Annual percentage } \\
\text { change }\end{array}$ \\
\hline 1 & China & 1899 & 10.4 & 20 & 1 & United States & 2,265 & 12.3 & 15 \\
\hline 2 & United States & 1481 & 8.1 & 16 & 2 & China & 1,743 & 9.5 & 25 \\
\hline 3 & Germany & 1474 & 8.1 & 17 & 3 & Germany & 1,254 & 6.8 & 19 \\
\hline 4 & Japan & 823 & 4.5 & 7 & 4 & Japan & 854 & 4.6 & 23 \\
\hline 5 & Netherlands & 660 & 3.6 & 15 & 5 & France & 715 & 3.9 & 17 \\
\hline 6 & France & 597 & 3.3 & 14 & 6 & United Kingdom & 636 & 3.5 & 13 \\
\hline 7 & Korea, Republic of & 555 & 3.0 & 19 & 7 & Netherlands & 597 & 3.2 & 16 \\
\hline 8 & Italy & 523 & 2.9 & 17 & 8 & Italy & 557 & 3.0 & 14 \\
\hline 9 & Russian Federation & 522 & 2.9 & 30 & 9 & Korea, Republic of & 524 & 2.9 & 23 \\
\hline 10 & Belgium & 476 & 2.6 & 17 & 10 & Hong Kong, China & 511 & 2.8 & 16 \\
\hline & & & & & & retained imports & 130 & 0.7 & 16 \\
\hline 11 & United Kingdom & 473 & 2.6 & 11 & 11 & Canada $^{a}$ & 462 & 2.5 & 15 \\
\hline 12 & Hong Kong, China & 456 & 2.5 & 12 & 12 & Belgium & 461 & 2.5 & 17 \\
\hline & domestic exports & 17 & 0.1 & 14 & & & & & \\
\hline & re-exports & 439 & 2.4 & 14 & & & & & \\
\hline 13 & Canada & 452 & 2.5 & 17 & 13 & India & 451 & 2.5 & 29 \\
\hline 14 & Singapore & 410 & 2.2 & 16 & 14 & Singapore & 366 & 2.0 & 18 \\
\hline & domestic exports & 224 & 1.2 & 23 & & & & & \\
\hline & re-exports & 166 & 1.0 & 10 & & & & & \\
\hline 15 & Saudi Arabia, Kingdom of & 365 & 2.0 & 45 & 15 & Spain & 362 & 2.0 & 11 \\
\hline 16 & Mexico & 350 & 1.9 & 17 & 16 & Mexico & 361 & 2.0 & 16 \\
\hline 17 & Taipei, Chinese & 308 & 1.7 & 12 & 17 & Russian Federation ${ }^{a}$ & 323 & 1.8 & 30 \\
\hline 18 & Spain & 297 & 1.6 & 17 & 18 & Taipei, Chinese & 281 & 1.5 & 12 \\
\hline 19 & India & 297 & 1.6 & 35 & 19 & Australia & 244 & 1.3 & 21 \\
\hline 20 & United Arab Emirates ${ }^{c}$ & 285 & 1.6 & 30 & 20 & Turkey & 241 & 1.3 & 30 \\
\hline
\end{tabular}

Source: WTO “World Trade Report 2012”, Appendix Table 3

1 Ver Cuadro 1.3, página 22 de WTO "World Trade Report 2012" 


\section{Pensamiento Crítico Vol. I8. Nº}

Ahora, mirando a los principales socios comerciales de las 4 economías en estudio, empezando con Japón, vemos en el Cuadro 5 que la importancia de China y Corea en su comercio se ha incrementado en los ultimos años, pero la de Taiwán disminuyo un poco. Del año 2005 al 2010 el porcentaje de exportaciones japonesas que va a China se incremento del $16.5 \%$ al $22.2 \%$ del total y las que van a Corea se incrementaron de $6.8 \%$ al $7.1 \%$ del total. En el caso de Taiwán, decreció del $6.4 \%$ en 2005 al $6.0 \%$ en el 2010 .

Cuadro 5: Merchandise trade of Japan by origin and destination 2010, Millions USD and percentage

\begin{tabular}{cccccccc}
\hline Exports & $\begin{array}{c}\text { Value } \\
\mathbf{2 0 1 0}\end{array}$ & $\begin{array}{c}\text { Share } \\
\mathbf{2 0 0 5}\end{array}$ & $\begin{array}{c}\text { Share } \\
\mathbf{2 0 1 0}\end{array}$ & Imports & $\begin{array}{c}\text { Value } \\
\mathbf{2 0 1 0}\end{array}$ & $\begin{array}{c}\text { Share } \\
\mathbf{2 0 0 5}\end{array}$ & $\begin{array}{c}\text { Share } \\
\mathbf{2 0 1 0}\end{array}$ \\
\hline Region & & & \multicolumn{5}{c}{ Region } \\
\hline World & 769,839 & 100.0 & 100.0 & World & 694,052 & 100.0 & 100.0 \\
Asia & 452,475 & 51.0 & 58.8 & Asia & 362,709 & 49.9 & 52.3 \\
\hline Economy & & & & Economy & & \\
\hline China & 16.5 & 22.2 & China & 21.0 & 22.1 \\
U.S. & 22.9 & 15.6 & U.S. & 12.7 & 10.0 \\
E.U. (27) & 14.8 & 11.3 & E.U. (27) & 11.4 & 9.6 \\
Korea & 6.8 & 7.1 & Australia & 4.7 & 6.4 \\
Taiwan & 6.4 & 6.0 & Saudi & 5.6 & 5.2 \\
Hong Kong & & 5.3 & 4.8 & U.A.E & 4.9 & 4.2 \\
Thailand & 3.8 & 4.4 & Korea & 4.8 & 4.1 \\
Singapore & 2.7 & 2.9 & Indonesia & 4.0 & 4.1 \\
Malaysia & 2.1 & 2.3 & Taiwan & 3.5 & 3.3 \\
Indonesia & 1.5 & 2.1 & Malaysia & 2.8 & 3.3 \\
\hline
\end{tabular}

Source: Table I.15, page 31, WTO "International Trade Statistics 2011" 


\section{Carlos Aquino Rodríguez}

China significa ahora más de un quinto del comercio de Japón.

La razón del fenómeno anterior es que China se convierte en un importante destino de las exportaciones de bienes finales debido a su enorme mercado de consumidores que incrementan constantemente su poder de compra.

También las exportaciones de partes y componentes a China para ensamblaje final se incrementa debido a la amplia mano de obra barata disponible en China, y en el caso de Taiwán más bien debido a los altos costos de su mano de obra por ejemplo algunas compañías japonesas con fabricas en Taiwán han mudado su producción a China. Tuve la oportunidad de ver esto por mi mismo en una visita a la Zona de Procesamiento de Exportaciones, ZPE, de Kaohsiung, una ciudad al sur de Taiwán el año 2012. Cuando hable a funcionarios de dos compañías japonesas ahí me dijeron que cada vez una mayor parte de su producción se va a China pero mantienen una parte en Taiwán, especialmente de los productos con mayor valor agregado ${ }^{2}$.

Aquí se puede ver la importancia del comercio en partes y componentes a lo largo de una cadena de suministro que involucra a las 4 economías asiáticas. En los ultimos años el surgimiento de las llamadas cadenas de valor global está teniendo un gran impacto en el comercio internacional. Veremos aquí como esta ópera y su importancia para la región asiática tal como lo pone un reporte del Banco Asiático de Desarrollo $(\mathrm{BAD})^{3}$ :

"Una implicación del surgimiento de las cadenas de producción global (global value chains, GVCs, en ingles) en las ultimos décadas es que el comercio internacional esta crecientemente dominado por el comercio en tareas, que está incorporado en los bienes intermedios que cruzan las fronteras varias veces para posterior procesamiento dentro de las GVCs. En la actualidad el comercio en partes intermedias significa más o

2 En una visita el 6 de Agosto del 2012, a la Nanzih Export Processing Zone, en Kaohsiung, en una entrevista con funcionarios de dos compañías Japonesas, Taiwan Futaba Electronics Corporation y Taiwan Brother Industries Ltd.

3 En su reporte anual "Asian Development Outlook 2012", paginas 20 y 21 http://www.adb.org/sites/ default/files/pub/2012/ado2012.pdf 


\section{Pensamiento Crítico Vol. I8. Nº}

menos las dos terceras partes del comercio internacional... Las GVCs se han expandido asimétricamente a través de muchas industrias, sobresaliendo predominantemente en los bienes duraderos como electrónicos y automóviles.

Las economías de Este y Sudeste Asiáticos (incluyendo Japón) han tomado un rol fundamental en las GVCs de bienes durables, efectivamente tornando la región en la "fabrica del mundo". Del 2000 al 2007, su participación en la exportación mundial de bienes durables subió del $35 \%$ al $42 \%$. Las exportaciones de las economías a lo largo de las GVCs están más fuertemente concentradas en los bienes durables que aquellos del resto del mundo (Grafico 1). Esto se debe en gran medida al rol de estas economías en los GVCs de los productos electrónicos: los electrónicos constituyen más de la mitad de los bienes durables exportados en el 2007 por la región (excepto para Vietnam, Indonesia, y Japón).

Grafico 1:

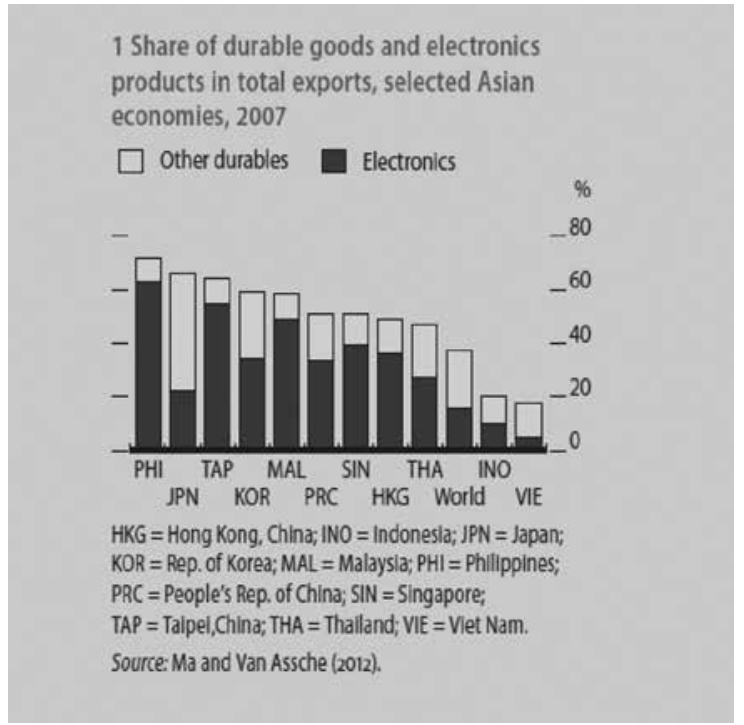

Source: "Asian Development Outlook 2012", page 20

Mientras que el comercio en bienes durables se ha concentrado en el Este y Sudeste Asiático, el consumo final de estos bienes permanece concentrado en Norte América y Europa. En el 2007, el 61\% de los bienes intermedios durables fueron comerciados 


\section{Carlos Aquino Rodríguez}

en las GVCs del Este y Sudeste Asiático, pero el 55\% de las exportaciones de bienes durables finales fueron a los países no asiáticos de la OECD.

Las economías juegan un rol distinto en las GVCs dependiendo de su nivel de desarrollo económico. El Grafico 2 posiciona a los países de acuerdo a su papel en las GVCs y su nivel de desarrollo. Las fases iníciales (upstream activities) como diseño, I y D y producción de sofisticados componentes están generalmente localizado en los países desarrollados, mientras que la manufactura y especialmente las actividades de ensamblaje final está localizado en los países en desarrollo. Finalmente, las actividades posteriores (downstream activities) de marketing y consumo otra vez tienen lugar en los países desarrollados.

Japón entonces se especializa en la producción upstream y exporta sofisticados bienes intermedios como semiconductores. Las nuevas economías industrializadas de altos ingresos (Hong Kong, China; la República de Corea; Singapur; y Taipéi, China) así como Malasia y Filipinas están localizadas en la mitad de la cadena donde se especializan en el procesamiento de bienes intermedios. Mientras que ellos importan bastantes bienes intermedios durables, los bienes intermedios también constituyen una proporción muy alta, mayor que el promedio, de sus exportaciones de bienes durables.

Los países de ingresos medianos, la República Popular China y Tailandia, se especializan en la producción downstream de ensamblaje de bienes duraderos finales. Ellos importan bastantes bienes intermedios durables, y se especializan en la exportación de bienes durables finales.

Finalmente, las economías occidentales de altos ingresos, principalmente EE.UU. y Europa, sirven como los mercados dominantes para los bienes finales, importando intensivamente bienes durables."

Así, las cuatro economías en estudio están involucradas en el proceso de la Global Value Chain. Japón exporta bienes de capital y sofisticados bienes intermedios, Corea y Taiwán están en la mitad de la cadena procesando bienes intermedios, y China hace el ensamblaje de bienes durables finales. El siguiente grafico, del mencionado reporte del $\mathrm{BAD}$, dibuja muy claramente este proceso de la GVC. 


\section{Pensamiento Crítico Vol. 18. No I}

\section{Gráfico 2:}

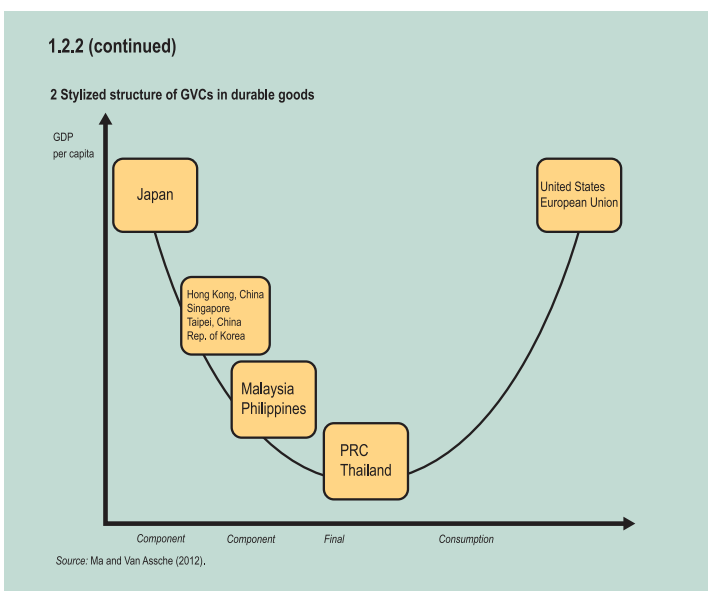

Source: "Asian Development Outlook 2012", page 21

El mejor ejemplo de cómo este proceso de GVC funciona es ver como se hace un iPad ${ }^{4}$. El producto es hecho con partes y componentes de Japón, Corea, Taiwán, entre otros. Finalmente es ensamblado en China por una compañía taiwanesa, Foxconn, y exportado a EE.UU. y al mundo entero para su consumo. Ver Grafico 3.

Pero ¿por qué este fenómeno de la GVC es cada vez más importante en la región asiática? Este se debe por supuesto a la ventaja comparativa de cada país, sea esta mano de obra barata para el ensamblaje del producto final en China, o la dotación de capital y tecnología para la producción de sofisticados bienes intermedios como en Japón. Pero en los ultimos años este fenómeno se ha acelerado como puede verse del creciente comercio entre los países asiáticos, debido a las políticas adoptadas por ellos. Estas son, las facilidades dadas para la inversión y el comercio, las políticas de acuerdos comerciales preferenciales, como los ALCs que están firmándose entre ellos.

Otra razón para la gran importancia de las GVC en la región del Asia es, como se menciona en un artículo publicado por el Profesor Richard Baldwin, el hecho de que

4 The Economist: Comparative advantage: "The Boomerang effect", April 21st, 2012 http://www.economist. com/node/21552898 


\section{Carlos Aquino Rodríguez}

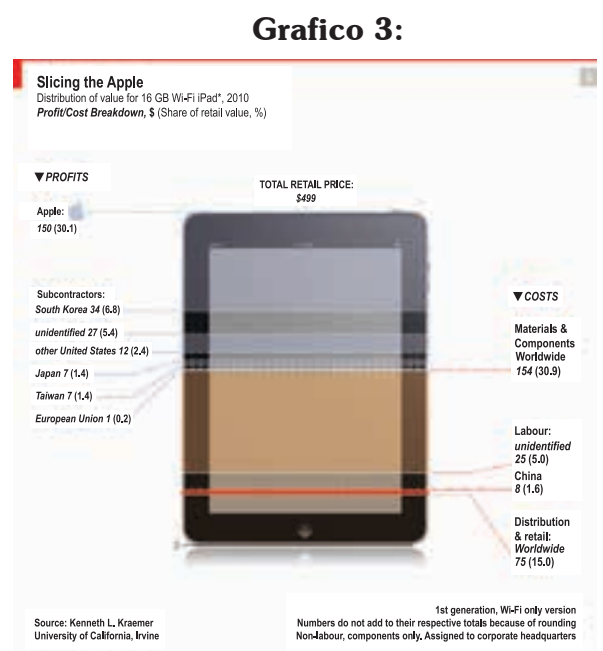

Source: The Economist, Comparative advantage: "The Boomerang effect", April 21st, 2012 http:// www.economist.com/node/21552898

esos países están localizados muy cerca uno del otro, es decir su proximidad geográfica 5 . Si ellos proveen trabajadores confiables, y un ambiente hospitalario para los negocios, como los hacen los países asiáticos, ellos pueden ser parte de la cadena de suministro.

Es interesante ver como los países asiáticos no estaban muy deseosos de firmar ALCs hasta la última década. Países en Europa y Latino América firmaban acuerdos desde los años 1960s. En la región asiática el único significativo ALC existente era entre los del Sudeste Asiático, los del grupo ASEAN. Pero ni uno de las cuatro economías en estudio tenía un ALC hasta el año 2000.

Fue Japón el primero en firmar un acuerdo y lo hizo con Singapur al comienzo de la década pasada. Luego siguió China, Corea y Taiwán, firmando ALCs con algunos países en la región o con otros fuera de esta como con Latino América. Pero aun el único acuerdo similar a un ALC entre ellos es el firmado entre China y Taiwán, el llamado Economic Cooperation Framework Agreement, ECFA. Firmado y en efecto desde el 2010, el ECFA es un acuerdo comercial preferencial que busca reducir aranceles y barreras comerciales entre los dos lados.

5 Richard baldwin: "trade and industrialisation after globalisation's 2nd unbundling: How building and joining a supply chain are different and why it matters" 


\section{Pensamiento Crítico Vol. I8. N I}

La racionalidad para un acuerdo comercial entre China y Taiwán fue el creciente comercio entre ellos y la necesidad de incrementar este. China y Taiwán tienen serias diferencias políticas, pero esto no fue obstáculo para que ellos tengan más comercio, inversión y ahora un creciente número de turistas yendo a ambos lados. Respecto al comercio por ejemplo, de acuerdo a estadísticas de Taiwán, las exportaciones a China fueron en 1993 de solo 16 millones de dólares, pero creció a 2.6 mil millones de dólares en 1999 y alcanzo 43.6 mil millones el año 2005. Las importaciones desde China fueron de 1 mil millones de dólares en 1993, 4.5 mil millones de dólares en 1999 y alcanzaron los 20 mil millones de dólares en el año 2005. ${ }^{6}$ Como se ve en el Cuadro 6 China es ahora el principal socio comercial de Taiwán y desde el año 2004 es el mayor destino para sus exportaciones.

Cuadro 6: Merchandise trade of Taiwan by origin and destination 2010, Millions USD and percentage

\begin{tabular}{lccccccc}
\hline Exports & $\begin{array}{l}\text { Value } \\
\mathbf{2 0 1 0}\end{array}$ & $\begin{array}{c}\text { Share } \\
\mathbf{2 0 0 5}\end{array}$ & $\begin{array}{c}\text { Share } \\
\mathbf{2 0 1 0}\end{array}$ & Imports & $\begin{array}{c}\text { Value } \\
\mathbf{2 0 1 0}\end{array}$ & $\begin{array}{c}\text { Share } \\
\mathbf{2 0 0 5}\end{array}$ & $\begin{array}{c}\text { Share } \\
\mathbf{2 0 1 0}\end{array}$ \\
\hline Region & & \multicolumn{5}{c}{ Region } \\
\hline World & 274,601 & 100.0 & 100.0 & World & 251,236 & 100.0 & 100.0 \\
Asia & & & \multicolumn{7}{c}{ Asia } \\
\hline Economy & & & Economy & & \\
\hline China & 22.0 & 28.0 & Japan & 25.2 & 20.7 \\
Hong Kong & 17.2 & 13.8 & China & 11.0 & 14.3 \\
U.S. & 14.7 & 11.5 & U.S. & 11.6 & 10.1 \\
Japan & 7.6 & 6.6 & Korea & 7.2 & 6.4 \\
Singapore & 4.1 & 4.4 & Saudi Arabia & 4.1 & 4.7 \\
Korea & 3.0 & 3.9 & Australia & 2.6 & 3.6 \\
Germany & 2.2 & 2.4 & Germany & 3.4 & 3.3 \\
Philippines & 2.2 & 2.2 & Malaysia & 2.9 & 3.1 \\
Malaysia & 2.2 & 2.2 & Singapore & 2.7 & 3.0 \\
Source: Taiwan Statistical Data Book 2011 & & & & \\
\hline
\end{tabular}

6 Cifras del Cuadro 11-9e, pagina 228, Taiwan Statistical Data Book 2011 


\section{Carlos Aquino Rodríguez}

Como se ve en el Cuadro 6, desde el año 2005 al 2010 los mercados de China y Corea se convierten en importantes para Taiwán, pero el de Japón disminuye algo. En el lado de las importaciones China se vuelve más importante mientras que la importancia de Japón y Corea decrecen. China se vuelve más importante en ambos lados pues sus consumidores demandan más bienes y también porque las compañías taiwanesas establecidas ahí demandan partes y componentes para el ensamblado final, como se ve en el caso de la compañía Foxconn que produce el iPad en sus fábricas en China. China también produce muchos bienes baratos que los taiwaneses compran. Respecto a Japón, este es aun la fuente más grande de sus importaciones pues las compañías taiwanesas le compran partes y componentes usados en la producción de bienes que Taiwán exporta (como se vio también en el caso de las compañías japonesas que producen en las ZPE de Taiwán mencionadas anteriormente).

Así que China ahora representa más de un cuarto de las exportaciones de Taiwán y esto se incrementara con el tiempo. Hay un gran mercado para los productos taiwaneses ahí, y aun mano de obra barata para las compañías taiwanesas que hacen ensamblaje final destinado para exportaciones al mundo entero. El ECFA puede acelerar esta mayor relación económica. También en agosto del año 2012 Taiwán y China firmaron un acuerdo de inversión ${ }^{7}$. Se espera que la inversión de ambos lados se incremente y que las disputas, especialmente por la inversión de empresas taiwanesas en China, se resolverán más fácilmente.

Dada la situación política de Taiwán, en que muchos países no lo reconocen como un estado soberano, su capacidad para firmar ALCs es limitado. Pero Taiwán, China, Japón, y Corea, están juntos en el Asia Pacific Economic Cooperation, el foro APEC, y en este grupo hay un proceso de liberalización comercial hecho unilateralmente.

Para Corea, como se ve en Cuadro 7, China y Japón están entre los 5 mayores socios comerciales y Taiwán aparece entre los 10 primeros. Casi un cuarto de las exportaciones de Corea van al mercado chino.

7 The China Post, August 10, 2012, "Chiang, Cheng seal cross-strait pacts": http://www.chinapost.com.tw/ taiwan/china-taiwan-relations/2012/08/10/350499/Chiang-Chen.htm 


\section{Pensamiento Crítico Vol. 18. No I}

Cuadro 7: Merchandise trade of Korea by origin and destination 2005 and 2011, Million USD

\begin{tabular}{|c|c|c|c|c|c|c|c|}
\hline Exports & $\begin{array}{l}\text { Value } \\
2011\end{array}$ & & $\begin{array}{l}\text { Value } \\
2005\end{array}$ & Imports & $\begin{array}{l}\text { Value } \\
2011\end{array}$ & & $\begin{array}{l}\text { Value } \\
2005\end{array}$ \\
\hline Region & & Region & & Region & & Region & \\
\hline World & 556,514 & World & 284,419 & World & 524,375 & World & 261,238 \\
\hline Asia & 314,206 & Asia & 146,914 & Asia & 234,404 & Asia & 126,033 \\
\hline Economy & & Economy & & Economy & & Economy & \\
\hline China & 134,205 & China & 61,915 & U.S. & 119,191 & Japan & 48,403 \\
\hline $\begin{array}{l}\text { Saudi } \\
\text { Arabia }\end{array}$ & 56,203 & U.S. & 41,343 & China & 86,426 & China & 38,648 \\
\hline $\begin{array}{l}\text { United } \\
\text { Kingdom }\end{array}$ & 55,736 & Japan & 24,027 & Japan & 68,302 & U.S. & 30,586 \\
\hline Japan & 39,713 & Hong Kong & 15,531 & $\begin{array}{l}\text { United } \\
\text { Kingdom }\end{array}$ & 47,400 & $\begin{array}{l}\text { Saudi } \\
\text { Arabia }\end{array}$ & 16,106 \\
\hline U.S. & 34,007 & Taiwan & 10,863 & $\begin{array}{l}\text { Saudi } \\
\text { Arabia }\end{array}$ & 44,567 & Australia & 9,859 \\
\hline $\begin{array}{l}\text { Hong } \\
\text { Kong }\end{array}$ & 30,975 & Germany & 10,304 & Canada & 36,976 & Germany & 9,774 \\
\hline Singapore & 20,855 & Singapore & 7,407 & Australia & 26,323 & Indonesia & 8,184 \\
\hline Taiwan & 18,198 & $\begin{array}{l}\text { United } \\
\text { Kingdom }\end{array}$ & 5,339 & France & 16,959 & Taiwan & 8,050 \\
\hline Indonesia & 13,563 & Indonesia & 5,046 & Taiwan & 14,698 & Malaysia & 6,012 \\
\hline Brazil & 11,824 & Malaysia & 4,608 & Malaysia & 10,464 & Singapore & 5,318 \\
\hline
\end{tabular}

Source: Korea, Ministry of Knowledge Economy "Balance of Trade by Country (2011)" http://www.mke. go.kr/language/eng/economic/key_view.jsp?seq $=24 \& \operatorname{srchType}=1 \& \operatorname{srchWord}=\& \mathrm{ctx}=$ Trade\&pageNo $=1$ \#

De acuerdo a estadísticas de Corea este país desde el año 2010 tiene un déficit comercial con EE.UU. En el 2011 este déficit comercial fue de 85,184 millones de dólares, como se ve en el Cuadro 6, pero de acuerdo a estadísticas de EE.UU. este país sigue teniendo un déficit comercial con Corea, y este alcanzo el monto de 13,346 millones de dólares en el año 20118.

8 De acuerdo al U.S. Department of Commerce, Unites States Census Bureau, Foreign Trade http://www. census.gov/foreign-trade/balance/c5800.html\#2011 


\section{Carlos Aquino Rodríguez}

Como se ha visto, China se ha convertido en el socio comercial más importante de Japón, Taiwán y Corea. Lo mismo está pasando en muchos países de Asia, y en el mundo entero.

Si miramos a los socios comerciales de China en el Cuadro 8, Japón, Corea y Taiwán están entre los diez más importantes. Especialmente en el lado de las importaciones Japón, Corea y Taiwán están entre los tres más importantes. Los tres representan casi un tercio de las importaciones de China.

Cuadro 8: Merchandise trade of China by origin and destination 2010, Millions USD and percentage

\begin{tabular}{|c|c|c|c|c|c|c|c|}
\hline Exports & $\begin{array}{l}\text { Value } \\
2010\end{array}$ & $\begin{array}{l}\text { Share } \\
2005\end{array}$ & $\begin{array}{l}\text { Share } \\
2010\end{array}$ & Imports & $\begin{array}{l}\text { Value } \\
2010\end{array}$ & $\begin{array}{l}\text { Share } \\
2005\end{array}$ & $\begin{array}{l}\text { Share } \\
2010\end{array}$ \\
\hline Region & & & & Region & & & \\
\hline World & $1,577,750$ & 100.0 & 100.0 & World & $1,396,240$ & 100.0 & 100.0 \\
\hline Asia & 731,959 & & & Asia & 834,956 & & \\
\hline Economy & & & & Economy & & & \\
\hline U.S. & 283,236 & & & Japan & 176,376 & & \\
\hline Hong Kong & 218,302 & & & Korea & 138,348 & & \\
\hline Japan & 121,043 & & & Taiwan & 115,738 & & \\
\hline Korea & 68,766 & & & China & 106,879 & & \\
\hline Germany & 68,047 & & & U.S. & 102,098 & & \\
\hline Netherland & 49,704 & & & Germany & 74,261 & & \\
\hline United Kingdom & 38,767 & & & Australia & 61,122 & & \\
\hline Singapore & 32,347 & & & Malaysia & 50,446 & & \\
\hline Italy & 31,139 & & & Brazil & 38,125 & & \\
\hline Taiwan & 29,674 & & & Thailand & 33,195 & & \\
\hline
\end{tabular}

Source: China Statistical Yearbook 2011

$\mathrm{Si}$ vemos solo las importaciones de manufacturas de China, se ve que la mayor parte viene de Asia. En el Cuadro 9 se ve que el 70\% de las importaciones de China de esos productos viene de esa región. 


\section{Pensamiento Crítico Vol. 18. Nº I}

Cuadro 9: Import of manufactures of China by origin, 2010 (Million USD and percentage)

\begin{tabular}{|c|c|c|c|c|c|}
\hline & Value & Share & $\begin{array}{c}\text { Annual } \\
\text { percentage } \\
\text { change } \\
2005-2010\end{array}$ & $\begin{array}{c}\text { Annual } \\
\text { percentage } \\
\text { change } \\
2009\end{array}$ & $\begin{array}{c}\text { Annual } \\
\text { percentage } \\
\text { change } \\
2010\end{array}$ \\
\hline \multicolumn{6}{|l|}{ Region } \\
\hline World & 894,420 & 100.0 & 13 & -8 & 32 \\
\hline Asia & & 70.1 & 17 & -4 & 30 \\
\hline \multicolumn{6}{|l|}{ Economy } \\
\hline Japan & & 18.2 & 12 & -12 & 36 \\
\hline $\begin{array}{l}\text { European Union } \\
\text { (27) }\end{array}$ & & 16.4 & 17 & -5 & 31 \\
\hline Korea & & 14.0 & 12 & -5 & 35 \\
\hline Taiwan & & 12.4 & 9 & -15 & 36 \\
\hline China & & 11.8 & 14 & -6 & 24 \\
\hline Above 5 & & 72.6 & & & \\
\hline U.S. & & 7.8 & 14 & -6 & 28 \\
\hline Malaysia & & 4.3 & 18 & 2 & 56 \\
\hline Thailand & & 2.9 & 19 & 0 & 30 \\
\hline Singapore & & 2.2 & 7 & -7 & 36 \\
\hline Philippines & & 1.5 & 3 & -41 & 30 \\
\hline
\end{tabular}

Source: WTO, "International Trade Statistics 2011", Table II.30, page 83

Lo que mayormente China importa de esos tres países es maquinaria, partes y componentes usados en el ensamblaje final de bienes.

Como se ve en el Cuadro 10 China incrementa año tras año su importancia como exportador de manufacturas pero también como importador de manufacturas. Su participación como exportador de manufacturas en el mundo se incremento de $1.9 \%$ en 1990 a $4.7 \%$ en el año 2000 y un $14.8 \%$ in el año 2010. También su participación como importador se incremento de $1.7 \%$ en 1990 a $8.7 \%$ en el año 2010. 


\section{Carlos Aquino Rodríguez}

Cuadro 10: Leading exporters and importers of manufactures, 2010, Billion USD and percentage

\begin{tabular}{|c|c|c|c|c|}
\hline & Value & $\begin{array}{c}\text { Share in World } \\
\text { Exports/Imports } \\
1990\end{array}$ & $\begin{array}{c}\text { Share in World } \\
\text { Exports/Imports } \\
2000\end{array}$ & $\begin{array}{c}\text { Share in World } \\
\text { Exports/Imports } \\
2010 \\
\end{array}$ \\
\hline \multicolumn{5}{|l|}{ Exporters } \\
\hline European Union (27) & 3,999 & & 42.9 & 40.1 \\
\hline China & 1,477 & 1.9 & 4.7 & 14.8 \\
\hline U.S. & 944 & 12.1 & 13.8 & 9.5 \\
\hline Japan & 680 & 11.5 & 9.6 & 6.8 \\
\hline Korea & 412 & 2.5 & 3.3 & 4.1 \\
\hline $\begin{array}{l}\text { Hong Kong } \\
\text { - domestic exports } \\
\text { - re-exports }\end{array}$ & $\begin{array}{l}373 \\
7 \\
366\end{array}$ & & & \\
\hline $\begin{array}{l}\text { Singapore } \\
\text { - domestic exports } \\
\text { - re-exports }\end{array}$ & $\begin{array}{l}254 \\
115 \\
139\end{array}$ & 1.6 & 2.5 & 2.6 \\
\hline Taiwan & 234 & 2.6 & 3.0 & 2.4 \\
\hline \multicolumn{5}{|l|}{ Importers } \\
\hline European Union (27) & 3745 & & 39.9 & 36.3 \\
\hline U.S. & 1369 & 15.4 & 19.8 & 13.3 \\
\hline China & 894 & 1.7 & 3.5 & 8.7 \\
\hline $\begin{array}{l}\text { Hong Kong } \\
\text { - retained imports }\end{array}$ & $\begin{array}{l}389 \\
23\end{array}$ & & & \\
\hline Japan & 347 & 4.1 & 4.3 & 3.4 \\
\hline Canada & 292 & 3.8 & 4.1 & 2.8 \\
\hline Mexico & 240 & 1.3 & 3.1 & 2.3 \\
\hline Korea & 240 & 1.8 & 2.0 & 2.3 \\
\hline $\begin{array}{l}\text { Singapore } \\
\text { - retained imports }\end{array}$ & $\begin{array}{c}202 \\
63\end{array}$ & 1.8 & 2.2 & 2.0 \\
\hline Russia & 188 & - & 0.6 & 1.8 \\
\hline Taiwan & 164 & 1.5 & 2.3 & 1.6 \\
\hline
\end{tabular}

Source: WTO, "International Trade Statistics 2011", Table II.31, page 84 


\section{Pensamiento Crítico Vol. 18. $\mathrm{N}^{\circ}$ I}

La presencia China es más evidente si vemos al comercio de equipos de oficina y telecomunicaciones, uno de los mayores grupos en las manufacturas. Como se ve en el Cuadro 11 China ahora es el más grande exportador de esos ítems.

Cuadro 11: Leading exporters and importers of office and telecom equipment, 2010, Billion USD and percentage

\begin{tabular}{|c|c|c|c|c|}
\hline & Value & $\begin{array}{c}\text { Share in World } \\
\text { Exports/Imports } \\
1990\end{array}$ & $\begin{array}{c}\text { Share in World } \\
\text { Exports/Imports } \\
2000\end{array}$ & $\begin{array}{l}\text { Share in World } \\
\text { Exports/Imports } \\
2010\end{array}$ \\
\hline \multicolumn{5}{|l|}{ Exporters } \\
\hline China & 449 & 1.0 & 4.5 & 28.0 \\
\hline European Union (27) & 364 & - & 29.2 & 22.7 \\
\hline $\begin{array}{l}\text { Hong Kong } \\
\text { domestic exports } \\
\text { re-exports }\end{array}$ & $\begin{array}{c}173 \\
2 \\
171\end{array}$ & & & \\
\hline U.S. & 135 & 17.3 & 15.9 & 8.4 \\
\hline $\begin{array}{l}\text { Singapore } \\
\text { domestic exports } \\
\text { re-exports }\end{array}$ & $\begin{array}{l}127 \\
56 \\
72\end{array}$ & 6.4 & 7.6 & 7.9 \\
\hline Korea & 97 & 4.8 & 6.1 & 6.0 \\
\hline Japan & 93 & 22.5 & 11.2 & 5.8 \\
\hline Taiwan & 81 & 4.7 & 6.0 & 5.1 \\
\hline \multicolumn{5}{|l|}{ Importers } \\
\hline European Union (27) & 516 & - & 33.8 & 29.5 \\
\hline U.S. & 285 & 21.1 & 21.2 & 16.2 \\
\hline China & 278 & 1.3 & 4.4 & 15.9 \\
\hline $\begin{array}{l}\text { Hong Kong } \\
\text { retained imports }\end{array}$ & $\begin{array}{c}182 \\
11\end{array}$ & - & - & - \\
\hline $\begin{array}{l}\text { Singapore } \\
\text { retained imports }\end{array}$ & $\begin{array}{l}88 \\
17\end{array}$ & 4.5 & 5.3 & 5.0 \\
\hline Japan & 82 & 3.7 & 6.0 & 4.7 \\
\hline Mexico & 57 & 1.5 & 2.9 & 3.2 \\
\hline Korea & 49 & 2.6 & 3.3 & 2.7 \\
\hline Malaysia & 48 & 1.9 & 3.2 & 2.7 \\
\hline Taiwan & 46 & 2.5 & 3.3 & 2.6 \\
\hline
\end{tabular}

Source: WTO, "International Trade Statistics 2011", Table II.42, page 96 


\section{Carlos Aquino Rodríguez}

Respecto a la inversión extranjera directa IED, en China, esta ha aumentado en los ultimos años como se ve en el Cuadro 12, Japón, Corea y Taiwán aparecen entre los diez más importantes en China.

Cuadro 12: China: Foreign Investment actually utilized by country or region, million USD

\begin{tabular}{lccccc}
\hline $\begin{array}{c}\text { Country } \\
\text { (Region) }\end{array}$ & $\begin{array}{c}\text { Foreign } \\
\text { Direct } \\
\text { Investment } \\
\mathbf{2 0 0 9}\end{array}$ & $\begin{array}{c}\text { Other } \\
\text { Foreign } \\
\text { Investment } \\
\mathbf{2 0 0 9}\end{array}$ & $\begin{array}{c}\text { Country } \\
\text { (Region) }\end{array}$ & $\begin{array}{c}\text { Foreign } \\
\text { Direct } \\
\text { Investment } \\
\mathbf{2 0 1 0}\end{array}$ & $\begin{array}{c}\text { Other } \\
\text { Foreign } \\
\text { Investment } \\
\mathbf{2 0 1 0}\end{array}$ \\
\hline Total & 90,032 & 1,771 & Total & 105,732 & 3,086 \\
\hline Hong Kong & 46,075 & & $\begin{array}{c}\text { Hong } \\
\text { Kong }\end{array}$ & 60,566 & \\
Virgin Islands & 11,298 & Virgin & 10,447 & \\
Japan & 4,104 & Islands & Singapore & 5,428 & 1,635 \\
Singapore & 3,604 & Japan & 4,038 & \\
Korea & 2,700 & U.S. & 3,017 & \\
Cayman Islands & 2,581 & Korea & 2,692 & \\
U.S. & 2,554 & Cayman & 2,498 & \\
Samoan & 2,020 & Islands & \\
Taiwan & 1,880 & Taiwan & 2,475 & \\
Germany & 1,216 & Samoan & 1,773 & \\
\hline
\end{tabular}

Source: China Statistical Yearbook 2011, Table 6-14

Si consideramos que la mayoría de la inversión que viene de Hong Kong, que aparece como el mayor inversor en China, viene de compañías de otros países que invierten desde Hong Kong pues es más fácil hacerlo desde este lugar, y si consideramos que la inversión desde Virgin Islands y Cayman Islands también son de compañas de otros países que toman ventaja de estos lugares con bajos impuestos para registrarse ahí, se puede ver que Japón, Corea y Taiwán están entre los más grandes inversores en China. 


\section{Pensamiento Crítico Vol. I8. Nº}

La IED es responsable por una significativa parte de la producción y exportación de China. Uno de las modalidades preferidas es la fabricación por contrato, un proceso que establece un acuerdo entre dos compañías. Como parte del acuerdo, una compañía produce partes y otros materiales a nombre de su cliente. Algunos países asiáticos usaron este camino para empezar y avanzar en su proceso de industrialización, y especialmente Taiwán hizo y continúa haciendo esto. Taiwán ha sido especialmente exitoso en esta estrategia como lo menciona la UNCTAD en su "World Investment Report 2011":

"La provincia Taiwán de China se transformo exitosamente en un poderío industrial a través de la fabricación por contrato, especialmente de electrónicos. Esta estrategia fue llevada a cabo después de la Segunda Guerra Mundial pues la economía poseía una fuerza laboral educada, una infraestructura desarrollada y un gran número de empresarios de PYMES en la manufactura y otras industrias. El Gobierno construyo sobre esto proveyendo un soporte político y soporte institucional con el objetivo de fomentar las capacidades locales, incluyendo establecimiento de lazos con compañías multinacionales. En el caso de electrónicos, la estatal Electronics Research and Services Organization, la Universidad Nacional Chiao Tung y el National Development Fund jugaron un significativo rol en el desarrollo de la industria. Las firmas locales y la economía han mejorado sus capacidades con el tiempo, y se movieron de la producción de bienes usando tecnología simple, a procesos más intensivos en capital y tecnología, y crecientemente a la innovación. Después de un periodo esta estrategia ha producido muchas compañías locales electrónicas de clase mundial como Acer, BenQ, Asus, Quanta, Foxconn, muchas de las cuales son ahora compañías multinacionales. Este proceso ha originado también un formidable clúster industrial en que la economía continua avanzando, hacia por ejemplo, los semiconductores. Tanto Taiwán Semiconductor Manufacturing Company (TSMC) y United Mircoelectronics Corporation (UMC), dos líderes globales productores de semiconductores, deben mucho al Gobierno por su existencia". 9

Los Cuadros 13 y Cuadro 14 muestran los 10 mayores fabricantes por contrato en el mundo de electrónicos y fabricación de semiconductores y muchos de estas compañías son de Taiwán. Muchas de estas compañías tienen sus operaciones en China.

9 UNCTAD, "World Investment Report 2011", pagina 164 http://www.unctad-docs.org/files/UNCTADWIR2011-Full-en.pdf 


\section{Carlos Aquino Rodríguez}

Las compañías van a China por la mano de obra barata disponible ahí, pero en los ultimos años los salarios se están incrementando y el gobierno chino tiene una política de subir los salarios para tratar de mitigar la creciente disparidad en el ingreso.

De otro lado, las exportaciones e importaciones de Hong Kong, y la inversión de Hong Kong es importante para China, así que no es sorpresa que el primer acuerdo comercial de China fue firmado con Hong Kong en el 2003. El Closer Economic Partnership Arrangement (CEPA) entre China y Hong Kong fue replicado otra vez en el que China firmo con Macao. Desde ese momento China empezó activamente la búsqueda de ALCs con socios dentro y fuera de Asia.

Tenemos un resumen de actuales ALCs en las cuatro economías en el Cuadro 15. Es una sorpresa ver como China, un país que recién hace 33 años se embarco en reformas económicas que dejaron atrás su economía socialista, tiene ahora más ALCs que economías capitalistas de más tiempo como Japón, Corea y Taiwán.

Cuadro 15: FTA Status (cumulative as of Jan. 2012)

\begin{tabular}{cccccc}
\hline Concluded & $\begin{array}{c}\text { Under } \\
\text { Negotiation }\end{array}$ & Total & $\begin{array}{c}\text { With Countries } \\
\text { Outside Asia }\end{array}$ & $\begin{array}{c}\text { With Countries } \\
\text { Inside Asia }\end{array}$ \\
\hline China & 12 & 6 & 18 & 9 & 9 \\
Japan & 13 & 2 & 15 & 5 & 10 \\
Korea & 9 & 7 & 16 & 10 & 6 \\
Taiwan & 5 & 2 & 7 & 6 & 1 \\
\hline
\end{tabular}

Source: ADB: Asian Economic Integration Monitor, July 2012, from table 20, page 45

Como se dijo antes, el único ALC entre los 4 países, es el que existe entre China y Taiwán, el ECFA. Pero tres de ellos, China, Japón, y Corea están buscando tener un ALC entre ellos. En Mayo del 2012 firmaron un acuerdo para promover la inversión ${ }^{10}$.

10 China Daily, May 13, 2012, "China, Japan and ROK ink investment deal": http://www.chinadaily.com.cn/ china/2012-05/13/content_15279774.htm 


\section{Pensamiento Crítico Vol. I8. N I}

\section{Cuadro 13:}

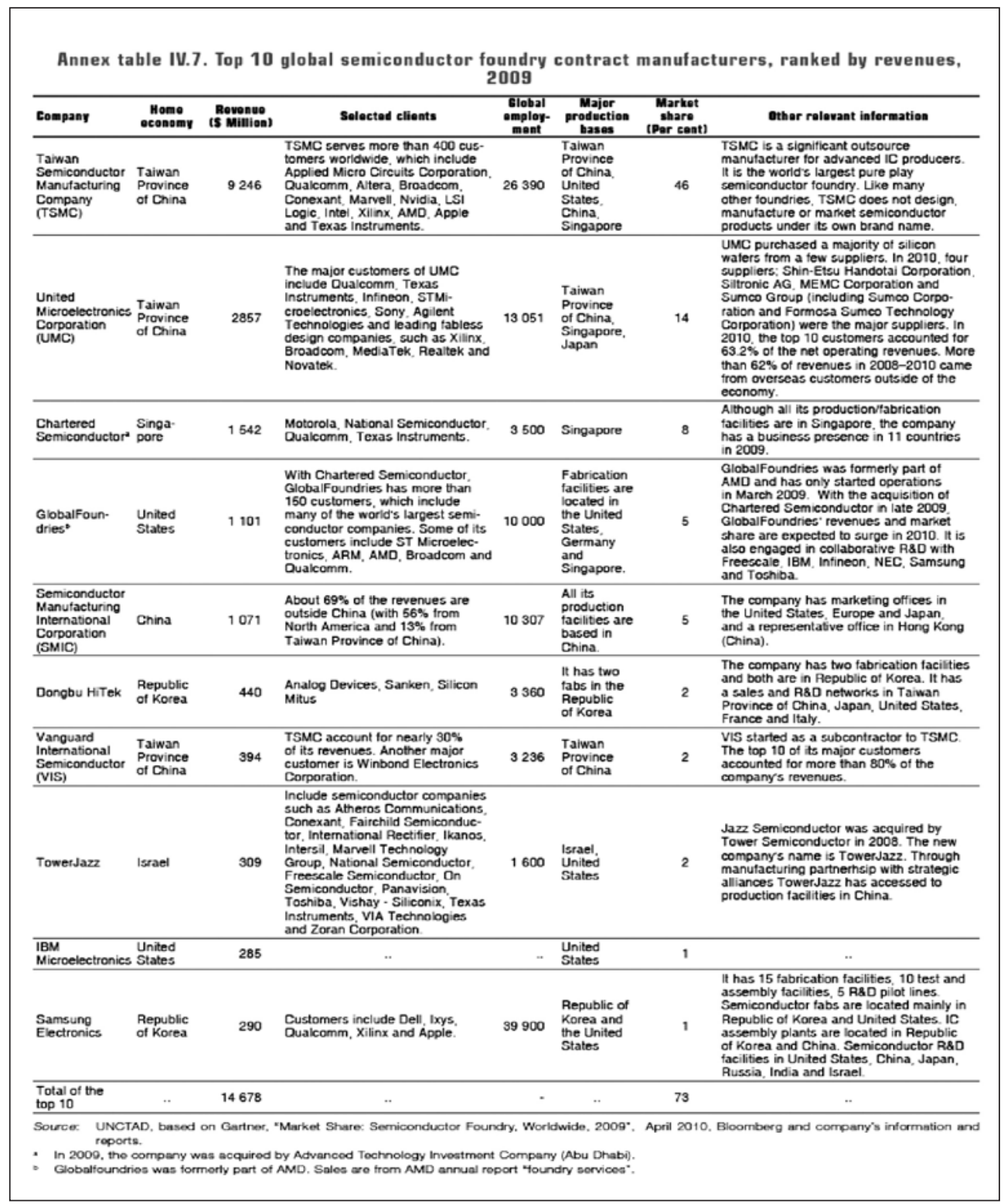




\section{Carlos Aquino Rodríguez}

\section{Cuadro 14:}

Annex table IV.1. Top 10 contract manufacturers in electronics, ranked by revenues, 2009:

\begin{tabular}{|c|c|c|c|c|c|c|}
\hline Company & $\begin{array}{c}\text { Home } \\
\text { economy }\end{array}$ & \begin{tabular}{|l|} 
Revenuas \\
(S billion)
\end{tabular} & Soloctod major clients & \begin{tabular}{|c|} 
Elobal \\
amployment \\
\end{tabular} & \begin{tabular}{|c|}
$\begin{array}{c}\text { Major ouerseas production } \\
\text { bases }\end{array}$ \\
\end{tabular} & Dther relerant information \\
\hline $\begin{array}{l}\text { Foxconn } \\
\text { Hon Hai }\end{array}$ & $\begin{array}{l}\text { Taiwan } \\
\text { Province } \\
\text { of China }\end{array}$ & 59.3 & $\begin{array}{l}\text { Apple Inc, Hewiett-Packard, Dell, } \\
\text { Nokia, Sony Ericsson, Samsung. } \\
\text { Microsoft, Acer, Intel, Samsung. } \\
\text { Cisco, Nintendo, Amazon }\end{array}$ & 611000 & $\begin{array}{l}\text { China, Malaysia, Viet Nam, } \\
\text { Czech Republic }\end{array}$ & $\begin{array}{l}\text { Manufacturing operations in many } \\
\text { countries. About } 20 \text { factories in China. }\end{array}$ \\
\hline Flextronics & Singapore & 30.9 & $\begin{array}{l}\text { Alcatel-Lucent, Cisco, Dell, } \\
\text { Sony Ericsson, Hewiett-Packard, } \\
\text { Huawei, Lenovo, Microsoft, } \\
\text { Eastman Kodak, Western Digtal, } \\
\text { Research in Motion, Motorola }\end{array}$ & 160000 & $\begin{array}{l}\text { Brazil, China, Hungary, } \\
\text { Malaysia, Mexico, Poland, } \\
\text { Ukraine, India }\end{array}$ & $\begin{array}{l}\text { Manufacturing facilities in } 30 \text { countries } \\
\text { covering the Americas, Europe and } \\
\text { Asia. }\end{array}$ \\
\hline Quanta & $\begin{array}{l}\text { Taiwan } \\
\text { Province } \\
\text { of China }\end{array}$ & 25.4 & $\begin{array}{l}\text { Apple Inc, Compaq. Dell, Hewiett- } \\
\text { Packard, Fujtsu, LG, Siemens AG, } \\
\text { Sony, Gateway, Cisco, Lenovo, } \\
\text { Siemens AG, Sharp Corporation, } \\
\text { Panasonic, Research in Motion, } \\
\text { Gericom, Toshiba }\end{array}$ & 64719 & $\begin{array}{l}\text { China, United States, } \\
\text { Germany }\end{array}$ & $\begin{array}{l}\text { Manulactuirng operations in the } \\
\text { Americas, Asia and Europe. A number } \\
\text { of factories are in China. }\end{array}$ \\
\hline Compal & $\begin{array}{l}\text { Taiwan } \\
\text { Province } \\
\text { of China }\end{array}$ & 20.4 & $\begin{array}{l}\text { Acer Inc, Dell, Toshiba, Hewlett- } \\
\text { Packard, Fujtsu-Siemens, Lenovo }\end{array}$ & 58025 & $\begin{array}{l}\text { China, Viet Nam, Poland, } \\
\text { Brazl, United States }\end{array}$ & Have a number of factories in China. \\
\hline Wistron & $\begin{array}{l}\text { Taiwan } \\
\text { Province } \\
\text { of China }\end{array}$ & 13.9 & $\begin{array}{l}\text { Acer, Sony, Dell, Microsoft, } \\
\text { Lenovo, FSC, Hewiett-Packard }\end{array}$ & 39239 & $\begin{array}{l}\text { China, Philippines, Czech } \\
\text { Republic, Mexico }\end{array}$ & $\begin{array}{l}\text { Wistron has R\&D centres in China } \\
\text { and the Netheriands. }\end{array}$ \\
\hline Inventec & $\begin{array}{l}\text { Taiwan } \\
\text { Province of } \\
\text { China }\end{array}$ & 13.5 & $\begin{array}{l}\text { Apple Inc, Acer, Hewiett-Packard, } \\
\text { Toshiba, Fujitsu-Siemens, Lenovo }\end{array}$ & 29646 & $\begin{array}{l}\text { China, Republic of Korea, } \\
\text { United States, Mexico, } \\
\text { United Kingdom, Czech } \\
\text { Republic, Malaysia } \\
\end{array}$ & $\begin{array}{l}\text { R\&D facilites in the United States, } \\
\text { United Kingdom and Japan. Software } \\
\text { and service outsourcing centres in } \\
\text { China. }\end{array}$ \\
\hline Jabil & $\begin{array}{l}\text { United } \\
\text { States }\end{array}$ & 13.4 & $\begin{array}{l}\text { Apple Inc, Hewiett-Packard, Cisco, } \\
\text { IBM, Echostar, NetApp, Pace, } \\
\text { Research in Motion, General } \\
\text { Electric }\end{array}$ & 61000 & $\begin{array}{l}\text { Brazil, Mexico, Austria, } \\
\text { United Kingdom, Germany. } \\
\text { France, Hungary, China, } \\
\text { Malaysia, Singapore, Viet } \\
\text { Nam }\end{array}$ & $\begin{array}{l}59 \text { manufacturing and design facilities } \\
\text { in over } 20 \text { countries covering the } \\
\text { Americas, Europe and Asia. }\end{array}$ \\
\hline $\begin{array}{l}\text { TPV } \\
\text { Technology }\end{array}$ & $\begin{array}{l}\text { Hong Kong. } \\
\text { China }\end{array}$ & 8.0 & $\begin{array}{l}\text { Dell, Hewlett-Packard, IBM, } \\
\text { Mitsubishi Electric }\end{array}$ & 24479 & $\begin{array}{l}\text { Mainly in China. Also in } \\
\text { Poland, Brazil and Mexico }\end{array}$ & $\begin{array}{l}\text { Also sell PC monitors under its } \\
\text { various own brands such as AOC } \\
\text { and Topview. } 2009 \text { revenues of PC } \\
\text { monitors was made up of } 31 \% \text { own } \\
\text { brand manufacturing (DBM) and } 69 \% \\
\text { original design manufacturing (DDM). } \\
\text { while LDC TV was } 12 \% \text { OBM and } \\
88 \% \text { ODM. }\end{array}$ \\
\hline Celestica & Canada & 6.5 & $\begin{array}{l}\text { Cisco, Hitachi, IBM, Research in } \\
\text { Moton }\end{array}$ & 35000 & $\begin{array}{l}\text { China, Malaysia, Singa- } \\
\text { pore, Thailand, Mexico, } \\
\text { United States, Czech } \\
\text { Republic, Ireland, Romania, } \\
\text { United Kingdom } \\
\end{array}$ & $\begin{array}{l}20 \text { manufacturing and design facilities } \\
\text { world wide. Celestica has a regional } \\
\text { technology centre in Thailand and a } \\
\text { global design services facility based in } \\
\text { Taiwan Province of China. }\end{array}$ \\
\hline Sanmina-SCI & $\begin{array}{l}\text { United } \\
\text { States }\end{array}$ & 5.2 & $\begin{array}{l}\text { IBM, Lenovo, Hewlett-Packard, } \\
\text { Cisco, Dell, Nokia, Caterpillar }\end{array}$ & 31698 & $\begin{array}{l}\text { Mexico, Brazil, Hun- } \\
\text { gary, Malaysia, Singapore, } \\
\text { China, Indonesia, Thailand }\end{array}$ & $\begin{array}{l}\text { Manufactures products in } 18 \\
\text { countries. }\end{array}$ \\
\hline $\begin{array}{l}\text { Total of } \\
\text { the top } 10\end{array}$ & $\ldots$ & 196.5 & .. & $\ldots$ & 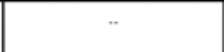 & - \\
\hline
\end{tabular}

Source. UNCTAD, based on date from Bloomberg and company annual reports.

- These companies are commonly referred to as "electronic manulacturing services "(EMS) providers. 


\section{Pensamiento Crítico Vol. I8. Nº}

De la misma forma empezaron negociaciones para tener un ALC entre los tres ${ }^{11}$. Pero por la a veces indecisión política de Japón es probable que las negociaciones entre China y Corea avancen más rápidamente.

Debe notarse que de los cuatro países en estudio, tres han firmado ALC con los miembros del grupo ASEAN. ASEAN, o la Association of South East Asian Nations, incluye a 10 paises: Brunei, Cambodia, Indonesia, Laos, Malasia, Myanmar, Filipinas, Singapur, Tailandia y Vietnam. Por ejemplo, el ALC entre China y ASEAN esta en efecto desde Enero del 2010 y estableció el tercer ALC mas grande del mundo, justo detrás de la European Union y el North American Free Trade Area ${ }^{12}$. Japón también tiene un ALC con ASEAN así como Corea.

La creación de un grupo de integración regional como el ASEAN plus 3, como es llamado el grupo de ASEAN con China, Japón y Corea, podría crear algo como lo que se expuso hace muchos años, una Comunidad del Este Asiático ${ }^{13}$.

Como se ha visto, varios países del grupo ASEAN son importantes socios comerciales de los 4 países en estudio. Malasia, Filipinas, Tailandia y Singapur aparecen entre los 10 mayores socios de China, Japón, Corea, y Taiwán. También, juntos esos 8 países están involucrados en el Global Value Chain en la región y los ALC entre ellos hacen más fácil el flujo de partes y componentes entre ellos e incrementa su relación comercial.

Pero Taiwán no está incluido en estos ALC, excepto el que tiene con China. Esto es un problema para Taiwán y sus empresarios que temen perder competitividad especialmente contra las compañías coreanas, porque estos producen algunos bienes similares a los taiwaneses como partes y componentes en la electrónica, sectores de información y tecnología, y también bienes finales en esos sectores.

11 BBC News, May 14, 2012," China, S. Korea and Japan set to begin free trade talks": http://www.bbc. co.uk/news/business-18055033

12 People`s Daily Online, April, 20, 2012, "ASEAN, China to become top trade partners": http://english. peopledaily.com.cn/90778/7794001.html

13 The Japan Times, June, 22, 2012, "An East Asian Community": http://www.japantimes.co.jp/text/ eo20120622mi.html\#.T-XMgLVo1uk 


\section{Carlos Aquino Rodríguez}

Lo que Taiwán puede hacer es tratar de entrar al grupo TPP, el Acuerdo de Asociación Transpacífico Este es un acuerdo multilateral de libre comercio que busca una mayor liberalización de las economías de la región Asia-Pacifico. Actualmente tiene 11 miembros: Australia, Brunei, Canadá, Chile, Malasia, México, Nueva Zelanda, Perú, Singapur, EE.UU., y Vietnam. Japón está discutiendo unirse. Todos estos países son miembros del foro APEC. Taiwán también es miembro del APEC. Debe tratar de entrar antes que China lo haga. Pero antes de tratar de entrar al TPP Taiwán debe alcanzar un acuerdo con los EE.UU. para tener un Trade and Investment Framework Agreement $(\mathrm{TIFA})^{14}$ con este.

Junto al incremento en el flujo de bienes y dinero, hay un incremento en el número de personas entre los cuatro países. Especialmente los chinos, muchos de los cuales se vuelve ricos rápidamente, están viajando en gran número. Ellos están entre los mayores grupos de turistas en Japón y Corea y son los mayores en Taiwán. Por ejemplo Taiwán registro 2.97 millones de visitantes en los primeros 5 meses del año 2012, y los chinos eran casi la mitad de ellos, de acuerdo a estadísticas del Ministry of the Interior (MOI) ${ }^{15}$.

Podemos ver como los flujos de comercio e inversión están ayudando a los países del Este Asiático a desarrollarse. Japón fue el primero en industrializarse, y luego los llamados tigres asiáticos, Corea, Hong Kong, Singapur y Taiwán, y ahora el resto del Sudeste Asiático mas China. Un elemento necesario en este proceso fue el factor humano, la necesaria mano de obra capacitada. Es interesante ver como por ejemplo mano de obra calificada, en este caso ingenieros de Japón, que se retiraron de su trabajo en su país al alcanzar la edad de jubilación, ahora se han ido a China a trabajar ahí y están ayudando a sus compañías a alcanzar competitividad internacional ${ }^{16}$.

Es este movimiento de personas, especialmente de fuerza labor educada, que algunos países en la región necesitaran, dado el hecho de que su población pronto

14 The China Post, August 15, 2012, "Taiwan plans to get US backing for trade": http://www.chinapost.com. tw/taiwan/national/national-news/2012/08/15/350995/Taiwan-plans.htm

15 Taiwan News, June 30, 2012, "China biggest source of visitors arrivals to Taiwan: MOI", http://www. taiwannews.com.tw/etn/news content.php?id=1959998

16 The China Post, April 18, 2012, "Aging engineers behind 'made in Japan' find second life in China": http:// www.chinapost.com.tw/business/company-focus/2012/04/18/338199/Aging-engineers.htm 


\section{Pensamiento Crítico Vol. I8. Nº}

empezara a decrecer. De hecho Japón ya experimenta un declive en su población desde hace 6 años y se proyecta que en 15 a 20 años más o menos lo mismo pasara con Corea y Taiwán.

\section{3. ¿Como y cuando China cambiara su motor de crecimiento de las exportaciones e inversión al consumo?}

Como se ve en el Cuadro 16 China está alcanzando un extraordinario crecimiento económico en los ultimos años. Desde que introdujo reformas económicas en 1979, el país ha estado creciendo a una tasa promedio anual de casi $10 \%$. El enorme mercado interno de China, debido a su gran población y consumidores con mayor poder de compra es una magneto para las compañías. Este hecho, de países como China que tienen gran población o en crecimiento es lo que esta haciendo posible que algunos países en desarrollo crezcan tan rápido en los ultimos años ${ }^{17}$.

El motor del crecimiento en China ha sido principalmente el sector exportador y la inversión. El país es ahora el mayor exportador en el mundo y la tasa de inversión es casi la mitad de su PBI. También la tasa de ahorro es muy alta, la más alta en el mundo, y el año 2009 esta alcanzo el 53.6\% de su PBI!

El problema es que China al depender de las exportaciones ha acumulado un enorme superávit comercial con muchos países, y muchos de ellos se quejan de prácticas desleales de empresas chinas para alcanzar ese objetivo, esto es, que hacen dumping, o que tiene una moneda subvaluada. También el otro motor de crecimiento, la inversión, ha causado problemas de sobre inversión en algunos sectores o inversión ineficiente.

Otro problema es su baja tasa de consumo. En muchos países la tasa de consumo está en un 60\% sobre el PBI o en EE.UU. esta en alrededor de un 70\% de su PBI, pero en China, como el Grafico 4 muestra, esta tasa ha estado decreciendo en estos años, y ahora es de menos del $40 \%$ de su PBI.

17 As indicated in a paper presented by Professor Hitoshi Hirakawa "Structural Shift of the World Economy and Institutionalization in East Asia", in a Workshop in Yokohama, Japan, July 22, 2012 


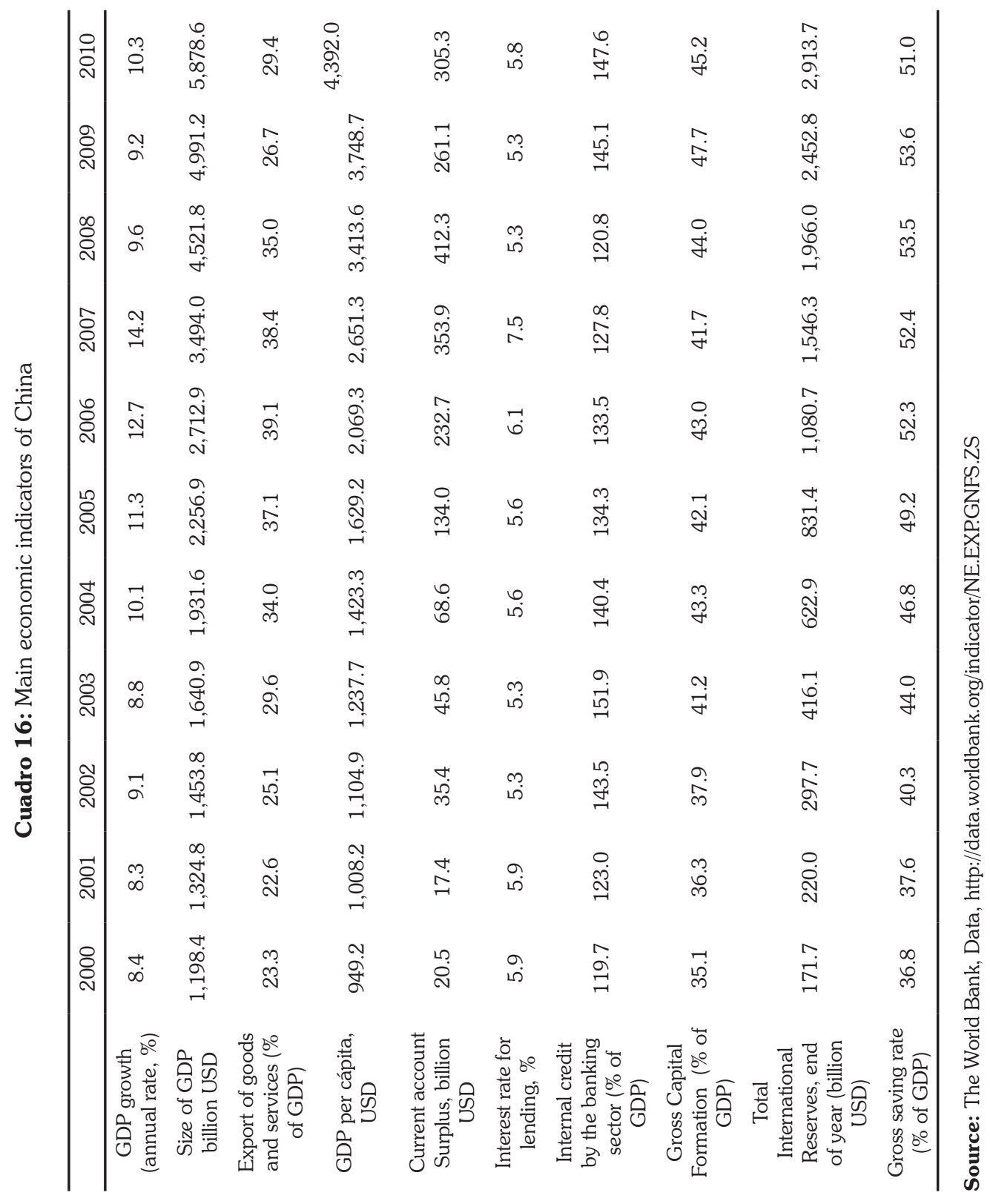




\section{Pensamiento Crítico Vol. 18. No I}

Grafico 4:

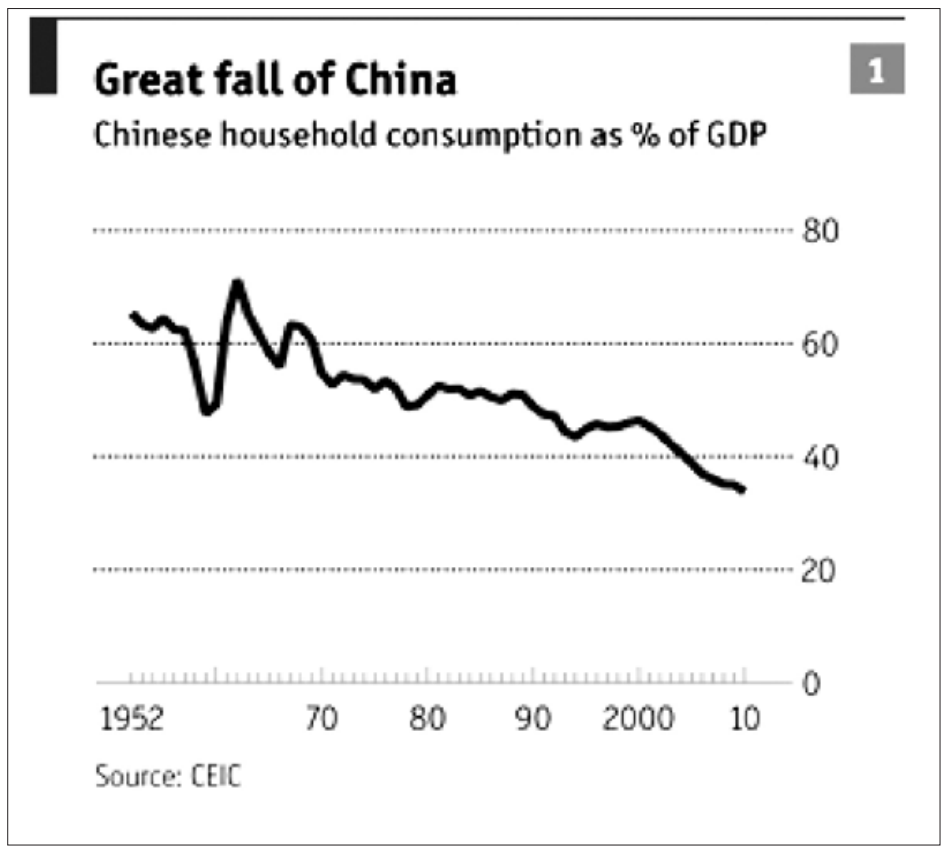

Source: The Economist "One-track behind": http://www.economist.com/node/21528985

El mundo pide a China que cambie el motor de su crecimiento de las exportaciones e inversión al consumo. El gobierno de China se da cuenta de que esto debe hacerse.

A finales del año 2008 cuando la economía mundial entro en una crisis que afecto China al decrecer la demanda por sus exportaciones, su gobierno tomo pasos para promover la demanda interna. Incremento la tasa de inversión pero también dio medidas para que las familias compren mas autos, bienes durables, y casas más fácilmente. Como resultado la venta de autos por ejemplo creció tan rápido que el siguiente año 2009 China paso a EE.UU. como el más grande mercado de autos en el mundo. Como se ve en el Cuadro 17, en el año 2009 la contribución al crecimiento del PBI del sector exportador fue negativo pero la inversión, el gasto de gobierno y el gasto privado creció más que el año anterior. Como resultado China pudo capear la crisis internacional y creció a 9.2\% mientras que muchos países registraron un crecimiento negativo. 


\section{Carlos Aquino Rodríguez}

Cuadro 17: Contribution to economic growth (in \%)

\begin{tabular}{cccccc}
\hline Year & $\begin{array}{c}\text { Private } \\
\text { Consumption }\end{array}$ & $\begin{array}{c}\text { Government } \\
\text { Consumption }\end{array}$ & Investment & Net Exports & GDP \\
\hline 2006 & 3.0 & 1.1 & 5.4 & 3.3 & 12.7 \\
2007 & 3.8 & 1.6 & 5.6 & 3.3 & 14.2 \\
2008 & 2.7 & 1.4 & 4.7 & 0.8 & 9.6 \\
2009 & 2.9 & 1.7 & 8.9 & -4.3 & 9.2 \\
2010 & 2.8 & 1.1 & 5.6 & 0.8 & 10.3 \\
\hline
\end{tabular}

Source: "Asia Development Outlook 2011: South-South Economic Links", April 2011 http://www.adb. org/sites/default/files/pub/2011/ado2011.pdf

En la presente situación internacional, cuando el año 2012 la economía mundial presente una tasa de crecimiento menor, y los países de la zona Euro tengan uno negativo, mientras que EE.UU. y Japón tendrán una tasa de menos de $2 \%$ o menos, otra vez el gobierno chino está tomando medidas para contrarrestar la baja demanda externa con una robusta demanda interna.

\section{4. ¿Como la apreciación el yuan podría acelerar el cambio de China como motor de la economía mundial?}

La moneda china, el Yuan, ha sido sujeto de mucho debate, especialmente porque algunos países, como EE.UU. y Europa, piensan que esta subvaluada, y esto da una ventaja desleal a los productos chinos vendidos en el mundo.

Por muchos años hasta julio del 2005 el Yuan estaba fijo a un valor de 8.2 Yuanes por dólar, pero desde ese momento empezó a apreciarse, hasta julio del 2008, en que alcanzo un precio de 6.8 por dólar. Ver Grafico 5. China permitió esto pues muchos países se habían quejado de su moneda subavaluada, y por el creciente superávit comercial y en cuenta corriente y de su creciente Reservas Internacionales.

Pero la crisis del 2008 hizo que las autoridades chinas detuvieron este proceso ante la desaceleración de sus exportaciones. El Yuan no se transa libremente, el gobierno mantiene un sistema de controles y fija el valor de su moneda permitiendo un pequeño 


\section{Pensamiento Crítico Vol. I8. N I}

margen de variación todos los días. Pero en Julio del 2010 las autoridades chinas permitieron otra vez que su moneda se empiece a apreciar y a Agosto del 2012, esta ha alcanzado un valor de alrededor de 6.35 Yuanes por dólar. Ver Grafico 5.

Grafico 5: Yuan exchange rate in USD (last 5 years)

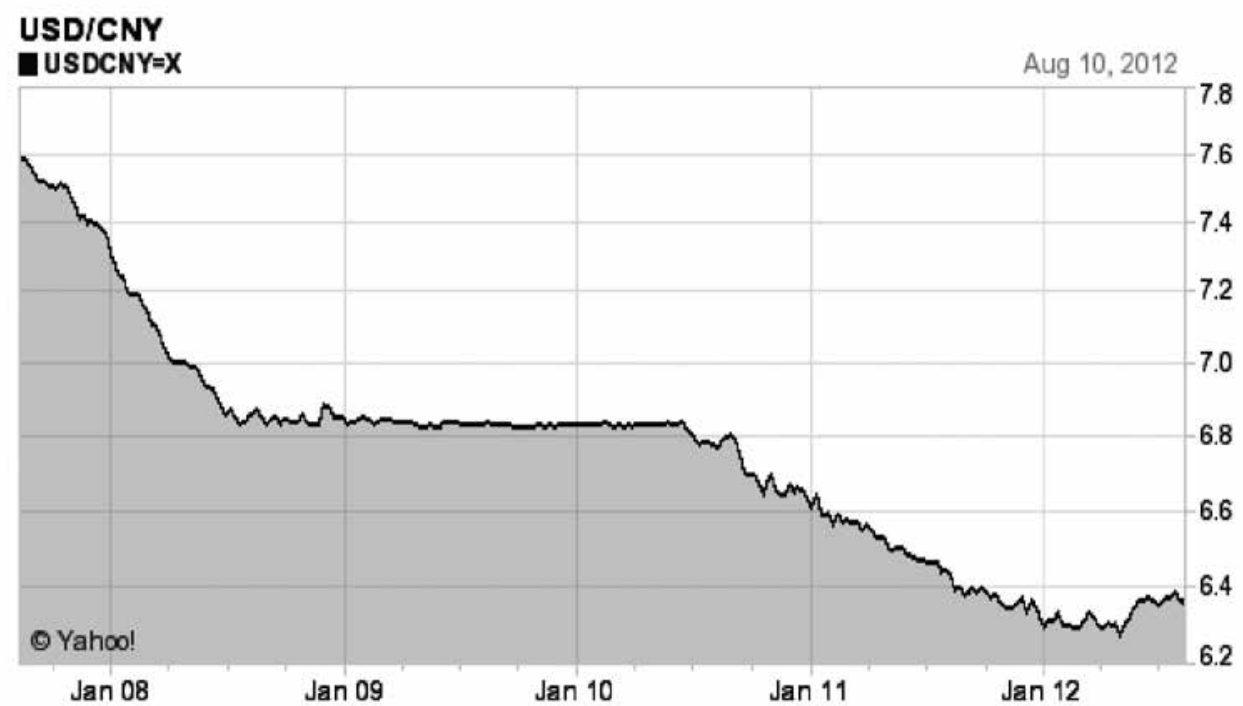

Source: Yuan exchange rate, 13th August 2012, was 6.35 per USD http://finance.yahoo.com/q/bc?s=USDC $\mathrm{NY}=\mathrm{X} \& \mathrm{t}=5 \mathrm{y} \& \mathrm{l}=\mathrm{on} \& \mathrm{z}=\mathrm{m} \& \mathrm{q}=1 \& \mathrm{c}=$

La moneda continuara apreciándose aunque a una tasa menor, esto incrementara el poder adquisitivo para comprar bienes del extranjero. Especialmente cuando las economías desarrolladas de Europa, Japón y EE.UU. no crecen mucho, el mundo necesita un nuevo motor de crecimiento. Se espera que China se convierta en este.

La apreciación del yuan será cuidadosamente manejada por las autoridades chinas. Temen que una rápida apreciación de su moneda haga perder competitividad a sus exportaciones y esto se traslade en una pérdida de empleos. 


\section{Carlos Aquino Rodríguez}

\section{CONCLUSIONES}

Hay un proceso de integración económica creciente en la región asiática, especialmente entre los 4 países, China, Japón, Corea y Taiwán. China juega un rol central en este como el país más grande en la región y el más populoso en el mundo que le da un enorme mercado interno.

El enorme mercado chino es una magneto que atrae a las compañías. Su mano de obra barata es otro imán, Como se ha visto China es un componente central de las global value chain que hacen que el comercio de partes y componentes se convierta en la parte central del proceso de integración económica que ocurre en la región. Y esto se acelerara con el tiempo.

La importancia de los acuerdos de libre comercio en Asia para una mayor integración económica es evidente. Hasta hace algunos años había un proceso de integración liderado por el mercado, la integración de facto. Pero ahora, cuando muchos países en el mundo firman ALC que les da tratamiento preferencial para sus productos, los países que no están en un ALC son discriminados. Así que ahora la integración económica en Asia está siendo institucionalizada por ALC. Ahora hay un proceso de integración liderado por los gobiernos.

Todo esto está haciendo de China y de la región del Este Asiático, la fábrica del mundo y un gran bloque económico. El centro económico del mundo se traslada de Occidente al Oriente. Para países como el Perú es imperativo incrementar sus relaciones con esa parte dinámica del mundo. El Perú tiene ALC con China, Japón y Corea. También tiene con Tailandia y Singapur. Perú es un miembro del foro APEC también. Perú también al hacer esto, podrá aprender de como esta parte del mundo se está desarrollando tan rápido.

Enero 2013 


\section{Pensamiento Crítico Vol. 18. No I}

\section{BIBLIOGRAFÍA}

ADB: Asian Economic Integration Monitor, July 2012

APEC: http://statistics.apec.org/

Baldwin Richard: "TRADE AND INDUSTRIALISATION AFTER GLOBALISATION'S 2ND UNBUNDLING: HOW BUILDING AND JOINING A SUPPLY CHAIN ARE DIFFERENT AND WHY IT MATTERS”, NBER WORKING PAPER SERIES, Working Paper 17716 http://siteresources.worldbank.org/INTRANETTRADE/Resources/ Baldwin_NBER_Working_Paper_17716.pdf

CEPD: Taiwan Statistical Data Book 2011

Hirakawa Hitoshi: "Structural Shift of the World Economy and Institutionalization in East Asia", in a Workshop on "Southeast Asian Economies and Asia Economic Integration", Yokohama National University, Yokohama, Japan, July 22, 2012

National Bureau of Statistics of China: "China Statistical Yearbook 2011" http://www. stats.gov.cn/tjsj/ndsj/2011/indexeh.htm

World Bank, "World Development Report 2012"

WTO : "World Trade Report 2012"

WTO: "International Trade Statistics 2011", 